Pesq. Vet. Bras. 38(1):59-64, janeiro 2018

DOI: $10.1590 / \mathrm{S} 0100-736 \mathrm{X} 2018000100010$

\title{
Aspectos patológicos e imuno-histoquímicos da polisserosite em búfalos (Bubalus bubalis) ${ }^{1}$
}

\author{
Maria A.S. Teixeira² ${ }^{2}$ Felipe Marlon Costa Machado² $^{2}$ Natália Maxine Ferreira Pinheiro \\ Sarmento ${ }^{2}$, Carlos Alberto Oliveira Júnior ${ }^{3}$, Gabriela Riet-Correa², Valíria Duarte \\ Cerqueira ${ }^{2}$, Ticiana do Nascimento França ${ }^{4}$ e Pedro Soares Bezerra Júnior ${ }^{2 *}$
}

\begin{abstract}
Teixeira M.A.S., Machado F.M.C., Sarmento N.M.F.P., Oliveira Júnior C.A., Riet-Correa G., Cerqueira V.D., França T.N. \& Bezerra Júnior P.S. 2018. [Histopathological and immunohistochemical study of the polyserositis in buffalo (Bubalus bubalis).] Aspectos histopatológicos e imuno-histoquímicos da polisserosite em búfalos (Bubalus bubalis). Pesquisa Veterinária Brasileira 38(1):59-64. Instituto de Medicina Veterinária, Universidade Federal do Pará, BR-316 Km 61, Bairro Saudade, Castanhal, PA 68746-360, Brazil. E-mail: psbezerrajunior@gmail.com

Polyserositis are inflammatory changes of the visceral and parietal serous of body cavities. A special type of polyserositis was identified in buffaloes in the 80s, being associated with infection by Chlamydia psittaci. Since these pioneering studies, there are no additional works about the condition. Considering the importance of buffalo in Pará, the zoonotic character of $C$. psittaci and the possibility of involvement of other agents in polyserositis in buffaloes the present study is proposed. We collected cases identified as polyserositis by sanitary inspection service in buffalo slaughtered for consumption in Belem for a complementary characterization of inflammatory cell and the research of Chlamydia spp antigens in lesions. Of 2.887 buffaloes slaughtered in a period of six months, there were 48 (1.66\%) cases of polyserositis and 39 analyzed. Santa Cruz do Arari in Marajó Island was the city with the highest frequency of cases, whereas $6.49 \%$ of buffaloes had lesions. However, $50 \%$ of the present study cases came from Soure municipality in Marajó Island, which provided about $49 \%$ of buffaloes slaughtered in the period. In the macroscopy, there were opaque areas with white-yellow thickening of the serous, sometimes with fibrous fringes on the surface. Histopathology showed connective tissue projections partially lined by cuboid or flattened mesothelial cells. Often in projections there were mononuclear infiltrate of variable intensity, consisting mainly of lymphoid cells, with occasional ectopic or tertiary lymphoid follicles.
\end{abstract}

INDEX TERMS: Polyserositis, buffalo, Bubalus bubalis, lymphocytic polyserositis, chlamydiosis, tertiary lymphoid tissue, pathology.

RESUMO.- Polisserosites são alterações inflamatórias das serosas viscerais e parietais das cavidades corpóreas. Um tipo especial destas alterações foi identificado em bubali-

\footnotetext{
${ }^{1}$ Recebido em 7 de março de 2017.

Aceito para publicação em 25 de maio de 2017.

${ }^{2}$ Programa de Pós-Graduação em Saúde Animal na Amazônia, Laboratório de Patologia Animal, Instituto de Medicina Veterinária, Universidade Federal do Pará (UFPA), BR-316 Km 61, Bairro Saudade, Castanhal, PA 68746360, Brasil. *Autor para correspondência: psbezerrajunior@gmail.com

${ }^{3}$ Instituto Federal de Educação, Ciência e Tecnologia do Pará (IFPA), UFPA, Campus de Castanhal, BR-316 Km 61, Castanhal, PA 68743-080.

${ }^{4}$ Laboratório de Patologia Animal, Departamento de Epidemiologia e Saúde Pública, Instituto de Veterinária, Universidade Federal Rural do Rio de Janeiro (UFRRJ), BR-465 Km 7, Seropédica, RJ 23890-000, Brasil.
}

nos abatidos para consumo nos anos 80 , sendo associada a infecção por Chlamydia psittaci. Apesar da importância da bubalinocultura no Pará, do caráter zoonótico da C. psittaci e da possibilidade de envolvimento de outros agentes na afecção, são raros trabalhos sobre a enfermidade desde os estudos pioneiros. No presente trabalho casos identificados como polisserosite pelo serviço de inspeção sanitária em búfalos abatidos para consumo foram coletados com objetivo de determinar a frequência e origem dos mesmos e de caracterizar as lesões e pesquisar antígenos de Chlamydia spp. nas mesmas. De um total de 2.887 bubalinos abatidos no período de estudo foram identificados 48 $(1,66 \%)$ casos. 0 município de Santa Cruz do Arari na Ilha 
de Marajó apresentou a maior porcentagem de casos em relação ao número de animais abatidos (6,49\%, 5/77). Na macroscopia as lesões se caracterizaram por áreas opacas, branco-amareladas de espessamento das serosas, por vezes com franjas fibrosas na superfície. Os resultados permitem concluir que os casos classificados como polisserosite pelos veterinários da inspeção sanitária nos búfalos abatidos para consumo correspondem na histopatologia a um tipo incomum de polisserosite, caracterizada por infiltrado linfocitário, com ocasionais formações de folículos linfoides terciários ou ectópicos. Foi observado ainda nestas lesões um predomínio de linfócitos T (CD3 positivos) no infiltrado, sendo os linfócitos B (CD79 positivos) presentes em maior número no interior das estruturas foliculares. Não foram demonstrados antígenos de clamídias nas lesões do presente estudo, o que demonstra a necessidade de estudos adicionais relativos a(s) etiologia(s) das lesões.

TERMOS DE INDEXAÇÃO: Polisserosite, búfalo, Bubalus bubalis, polisserosite linfocitária, clamidiose, tecido linfoide terciário, patologia.

\section{INTRODUÇÃO}

0 búfalo é um animal originário do continente asiático, pertencente à família Bovidae, subfamília Bovinae e espécie $B u$ balus bubalis. (Damasceno et al. 2010). 0 rebanho bubalino brasileiro está estimado em torno de 1,15 milhão de cabeças, estando a região Norte com 720 mil animais, e como a maior produtora do País, destacando-se o estado do Pará, que responde por 39\% do rebanho nacional (MAPA 2015).

A Bubalinocultura é considerada uma boa opção econômica em ambientes tropicais e, associado ao grande poder de adaptabilidade e rusticidade dos búfalos, tem-se mostrado relevante instrumento de progresso social (Bernardo 2007). Entretanto, um dos entraves à atividade são os problemas sanitários que, além de comprometer a produção, podem trazer riscos à saúde pública. Entre estes problemas está a polisserosite identificada em bubalinos abatidos para consumo no Pará na década de 80 e associada à infecção por Chlamydia psittaci (Freitas 1986, Freitas \& Machado 1988, Freitas et al. 1995). A lesão nesta afecção é caracterizada por espessamento focal ou disseminado nas serosas, em alguns casos na forma de vilosidades ou filamentos. Na microscopia há fibrose nas serosas com elevações papiliformes contendo linfócitos, monócitos e células mesoteliais com sinais de hiperplasia e metaplasia (Freitas 1986). Lesões macroscopicamente semelhantes as descritas por Freitas (1986) também são relatadas por Oliveira et al. (2016) sendo caracterizadas como linfomas multicêntricos de células B.

Decorridas mais de três décadas dos primeiros estudos de Freitas (1986) poucos relatos adicionais da afecção foram encontrados na literatura nacional (Ribeiro et al. 2015). Assim, estudos complementares sobre o tema se mostram importantes, principalmente considerando a importância e o crescimento da bubalinocultura no estado do Pará, o caráter zoonótico da C. psittaci e a possibilidade de envolvimento de outros agentes na polisserosite.

No presente trabalho o objetivo foi avaliar a frequência, origem e aspectos patológicos de casos de polisserosite em búfalos abatidos para consumo em um estabelecimento na região metropolitana de Belém do Pará, em um período de seis meses. As lesões foram submetidas à histopatologia e imuno-histoquímica para caracterização complementar do processo inflamatório e para pesquisa de antígenos de Chlamydia spp.

\section{MATERIAL E MÉTODOS}

Os casos descritos no presente estudo foram obtidos no acompanhamento do abate em bubalinos no matadouro localizado na região metropolitana de Belém no período de 5 de outubro de 2015 a 14 de abril de 2016. A origem dos bubalinos foi determinada pela observação da Guia de Trânsito Animal (GTA).

Os veterinários do SIE (Serviço de Inspeção Estadual) e o responsável técnico do estabelecimento classificaram como polisserosite casos onde havia espessamento e opacidade das serosas das cavidades torácicas, abdominal e/ou pericárdica, sendo os órgãos e carcaças afetados encaminhados ao Departamento de Inspeção Final (DIF). No DIF foram coletados fragmentos que incluíam as serosas do coração, fígado, diafragma e pulmão. As áreas foram selecionadas com base em estudo prévio (Freitas 1986), sendo coletadas amostras dos quatro órgãos mesmo que apenas um apresentasse lesão macroscópica. De 48 bubalinos com lesões foram coletadas amostras de 39. Os fragmentos foram fixados em formol a $10 \%$ tamponado com fosfatos por um período de 24 à 48h, desidratados em álcool etílico, diafanizados em xilol e incluídos em parafina. Cortes de $5 \mu \mathrm{m}$ foram corados com hematoxilina e eosina (HE) e visualizados em microscópico óptico. Cortes selecionados foram corados também com azul de toluidina, para identificação de mastócitos, e pela coloração de Ziehl Neelsen, para visualização de bacilos álcool ácido resistentes (BAAR).

A identificação imuno-histoquímica (IHQ) de linfócitos B e linfócitos T foi realizada na Universidade Federal Rural do Rio de Janeiro (UFRRJ), sendo utilizado protocolos pré-estabelecidos (Maley et al. 2006) com adaptações. Para tal foram selecionados tecidos de 7 bubalinos, com lesões inflamatórias moderadas a acentuadas. Como anticorpos primários foram utilizados para identificação de linfócitos $\mathrm{T}$ anticorpos monoclonais anti-CD3 produzido em camundongos (VMRD, catálogo MMIA), e para linfócitos B, anticorpos monoclonais anti-CD79 $\alpha$ cy (Dako, clone HM57), nas diluições de 1:50 e 1:25, respectivamente. A recuperação antigênica foi realizada com tampão citrato, para linfócito T, e com tampão TRIS-EDTA, para linfócito B, ambos em banho Maria a $98^{\circ} \mathrm{C}$ e por 15 minutos.

Para pesquisa IHQ de antígenos de Chlamydia spp. foi utilizado protocolo pré-estabelecido (Jelocnik et. al. 2014) com adaptações. Como anticorpo primário foi empregado o anticorpo monoclonal anti-lipopolissacarídio (LPS) de Chlamydia sp. produzido em camundongos (Progen Biotechinik, catálogo ACI-C) na diluição de 1:25. Para recuperação antigênica foi utilizada a proteinase $\mathrm{K}$ (Dako ${ }^{\circledR}$ proteinase K ready to use, catálogo S3020) por 5 minutos incubada a $37^{\circ} \mathrm{C}$. Como controle positivo foram utilizados cortes de tecidos de casos confirmados de clamidiose por Chlamydophila psittaci em psitacídeos (Casagrande et al. 2014), gentilmente cedidos pelo Prof. Dr. David Driemeier da Faculdade de Veterinária, Universidade Federal do Rio Grande do Sul (UFRGS). Como controles negativos foram empregados cortes duplicados, sendo o anticorpo primário substituído por PBS na incubação.

\section{RESULTADOS}

De um total de 2.887 bubalinos abatidos no período de estudo $48(1,66 \%)$ apresentaram as lesões nas serosas das cavidades torácica, abdominal e/ou pericárdica (Quadro 
1). Destes 48 casos, 25 (52,08\%) foram oriundos do município de Soure, na ilha do Marajó, sendo que este município forneceu mais da metade dos búfalos abatidos no período (51,78\%). 0 município de Santa Cruz do Arari apresentou a maior porcentagem de casos em relação ao número de animais abatidos $(6,49 \%, 5 / 77)$.

Macroscopicamente os órgãos apresentaram serosa com áreas opacas de espessamento, com superfície irregular e brilhante, por vezes com franjas fibrosas. A distribuição das lesões variou de multifocais a coalescentes, ou difusas (Fig.1 e Fig.2). Em 18 dos 39 bubalinos avaliados todos os quatro órgãos coletados apresentavam alterações

\section{Quadro 1. Polisserosite em búfalos abatidos para consumo} de outubro de 2015 a abril de 2016

\begin{tabular}{|c|c|c|c|c|}
\hline № & Municípios & $\begin{array}{l}\text { Número de } \\
\text { búfalos } \\
\text { abatidos (\%) }\end{array}$ & $\begin{array}{l}\text { Número de } \\
\text { búfalos com } \\
\text { lesões (\%) }\end{array}$ & $\begin{array}{c}\text { Porcentagem de } \\
\text { búfalos abatidos com } \\
\text { lesões por município }\end{array}$ \\
\hline 1 & Soure & $1.495(51,78 \%)$ & $25(52,08 \%)$ & $1,67 \%$ \\
\hline 2 & $\begin{array}{l}\text { Cachoeira } \\
\text { do Arari }\end{array}$ & $492(17,04 \%)$ & $8(16,66 \%)$ & $1,63 \%$ \\
\hline 3 & Chaves & $277(9,59 \%)$ & $3(6,25 \%)$ & $1,08 \%$ \\
\hline 4 & Ponta de Pedras & $237(8,20 \%)$ & 0 & 0 \\
\hline 5 & Santa Bárbara & $98(3,39 \%)$ & $5(10,41 \%)$ & $5,10 \%$ \\
\hline 6 & $\begin{array}{c}\text { Santa Cruz } \\
\text { do Arari }\end{array}$ & $77(2,66 \%)$ & $5(10,41 \%)$ & $6,49 \%$ \\
\hline 7 & Salvaterra & $73(2,52 \%)$ & $1(2,08 \%)$ & $1,37 \%$ \\
\hline 8 & Pacajá & $33(1,14 \%)$ & 0 & 0 \\
\hline 9 & $\begin{array}{l}\text { Santa Luzia } \\
\text { do Pará }\end{array}$ & $20(0,69 \%)$ & $1(2,08 \%)$ & $5,00 \%$ \\
\hline 10 & Marapanim & $18(0,62 \%)$ & 0 & 0 \\
\hline 11 & Inhangapí & $17(0,58 \%)$ & 0 & 0 \\
\hline 12 & Terra alta & $12(0,41 \%)$ & 0 & 0 \\
\hline 13 & Anapú & $10(0,34 \%)$ & 0 & 0 \\
\hline 14 & Ananindeua & $8(0,27 \%)$ & 0 & 0 \\
\hline 15 & Viseu & $7(0,24 \%)$ & 0 & 0 \\
\hline 16 & Xinguara & $5(0,17 \%)$ & 0 & 0 \\
\hline 17 & $\begin{array}{c}\text { Novo } \\
\text { Repartimento }\end{array}$ & $4(0,13 \%)$ & 0 & 0 \\
\hline 18 & Vigia & $4(0,13 \%)$ & 0 & 0 \\
\hline Total & & 2.887 (100\%) & $48(100 \%)$ & - \\
\hline
\end{tabular}

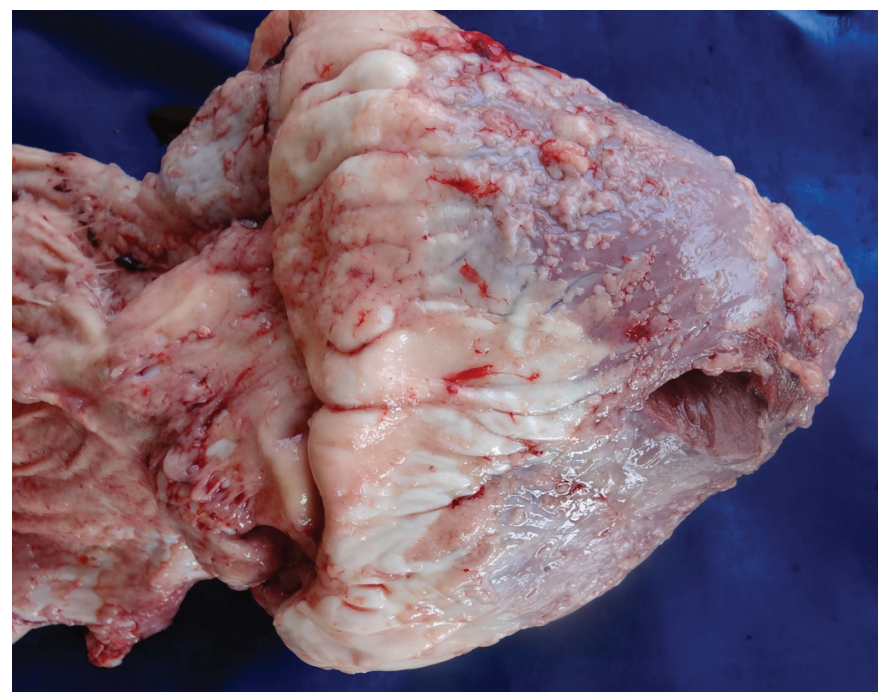

Fig.1. Coração com lesões nodulares branco-amareladas multifocais coalescentes no epicárdio, na polisserosite de búfalo abatido em matadouro.

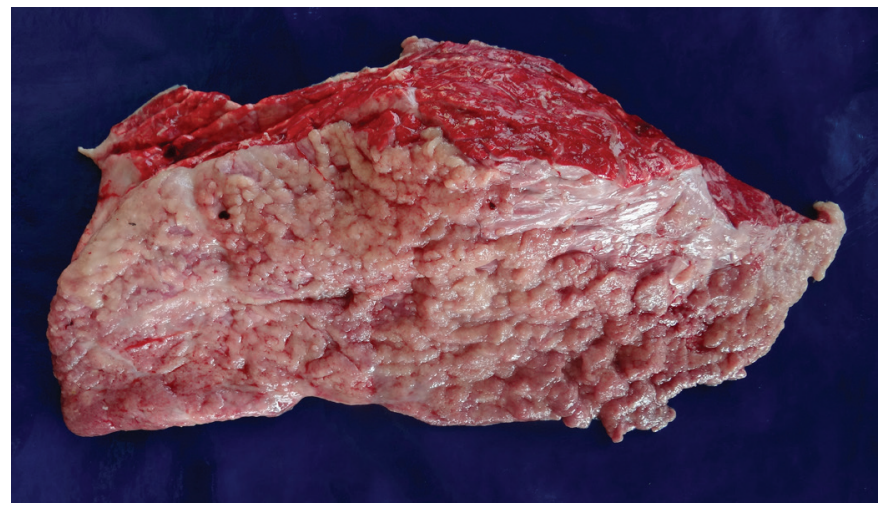

Fig.2. Pulmão com espessamento difuso da pleura, demonstrando opacidade e superfície esbranquiçada e irregular, na polisserosite de búfalo abatido em matadouro.

macroscópicas, porém em 7 casos apenas um dos órgãos foi afetado. Sete dos 39 bubalinos com lesões nas serosas apresentaram granulomas tuberculoides concomitantes no parênquima dos órgãos.

Na histopatologia as lesões se caracterizavam por espessamento da serosa, proliferação de tecido conjuntivo fibroso com frequente formação de projeções para o lúmen das cavidades (Quadro 2). Estas projeções encontravam-se total ou parcialmente revestidas por células mesoteliais, que em muitas áreas apresentam tumefação e aspecto cuboidal. As projeções fibrosas em 30 dos casos estavam

Quadro 2. Polisserosite em búfalo. Intensidade dos principais achados histopatológicos

\begin{tabular}{clc}
\hline \multirow{2}{*}{ Órgãos } & \multicolumn{2}{c}{ Achados histopatológicos nas serosas } \\
\cline { 2 - 3 } & \multicolumn{1}{c}{ Projeções fibrosas } & Inflamação linfocitária \\
\hline Coração & $\mathrm{L}(09) * ; \mathrm{M}(11) ; \mathrm{A}(02)$ & $\mathrm{L}(14) ; \mathrm{M}(04) ; \mathrm{A}(06)$ \\
Fígado & $\mathrm{L}(12), \mathrm{M}(08), \mathrm{A}(00)$. & $\mathrm{L}(17), \mathrm{M}(05), \mathrm{A}(01)$. \\
Pulmão & $\mathrm{L}(21), \mathrm{M}(05), \mathrm{A}(03)$. & $\mathrm{L}(08), \mathrm{M}(01), \mathrm{A}(03)$. \\
Diafragma & $\mathrm{L}(03), \mathrm{M}(08), \mathrm{A}(04)$. & $\mathrm{L}(06), \mathrm{M}(04), \mathrm{A}(07)$.
\end{tabular}

$\mathrm{L}=$ Leve; $\mathrm{M}$ = Moderada; $\mathrm{A}=$ Acentuada.

* Número de animais.

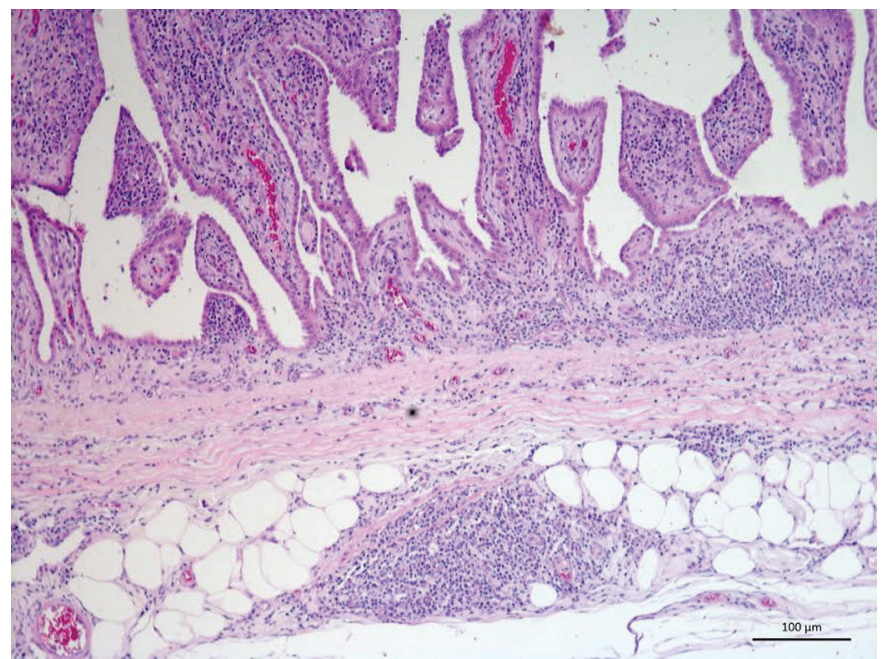

Fig.3. Diafragma apresentando projeções fibrosas na serosa com infiltrado linfocitário moderado e revestimento com células mesoteliais tumefeitas ou cuboidais, na polisserosite de búfalo abatido em matadouro. HE, obj.20x. 


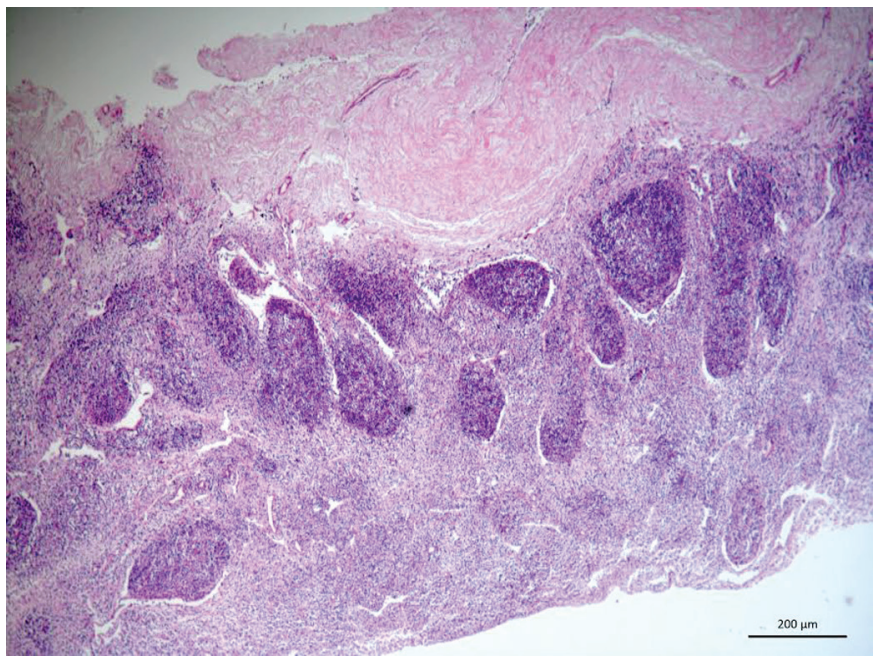

Fig.4. Pulmão apresentando infiltrado linfocitário na pleura com formação de folículos ectópicos, na polisserosite de búfalo abatido em matadouro. HE, obj.10x.

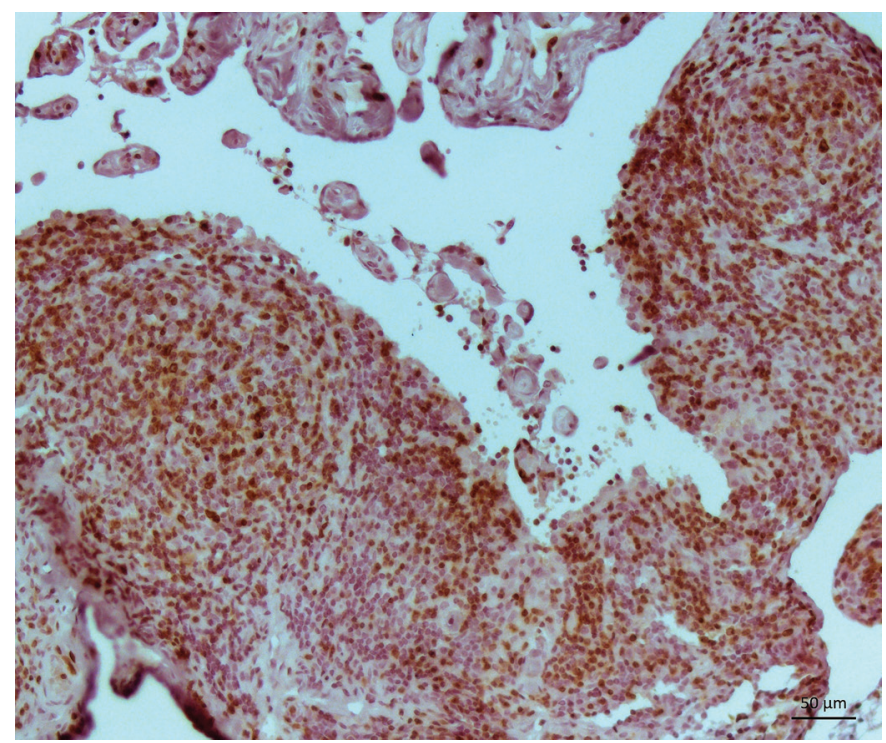

Fig.5. Imuno-histoquímica de diafragma com linfócitos T marcados por anticorpos monoclonais anti-CD3, na polisserosite de búfalo abatido em matadouro. HE, obj.40x.

preenchidas por infiltrado mononuclear, constituído predominantemente por células linfoides, em vários graus de intensidade. Em 8 casos foram observados aglomerados de células linfoides formando estruturas semelhantes a folículos linfoides isolados ou aglomerados (folículos linfoides ectópicos ou terciários) (Fig.3 e Fig.4). Os granulomas tuberculoides visualizados em sete búfalos eram caracterizados por centros de necrose caseosa com grumos basofílicos de mineralização distrófica, margeados por macrófagos, células epitelioides, células gigantes de Langhans, linfócitos e tecido conjuntivo fibroso.

A grande maioria das células linfoides foram positivas na IHQ com o anticorpo anti-CD3, com menor frequência de positividade para o anticorpo anti-CD79, indicando um predomínio de linfócitos T no infiltrado (Fig.5 e Fig.6).

Não foram encontrados antígenos de Chlamydia spp. nas lesões avaliadas por imuno-histoquímica.

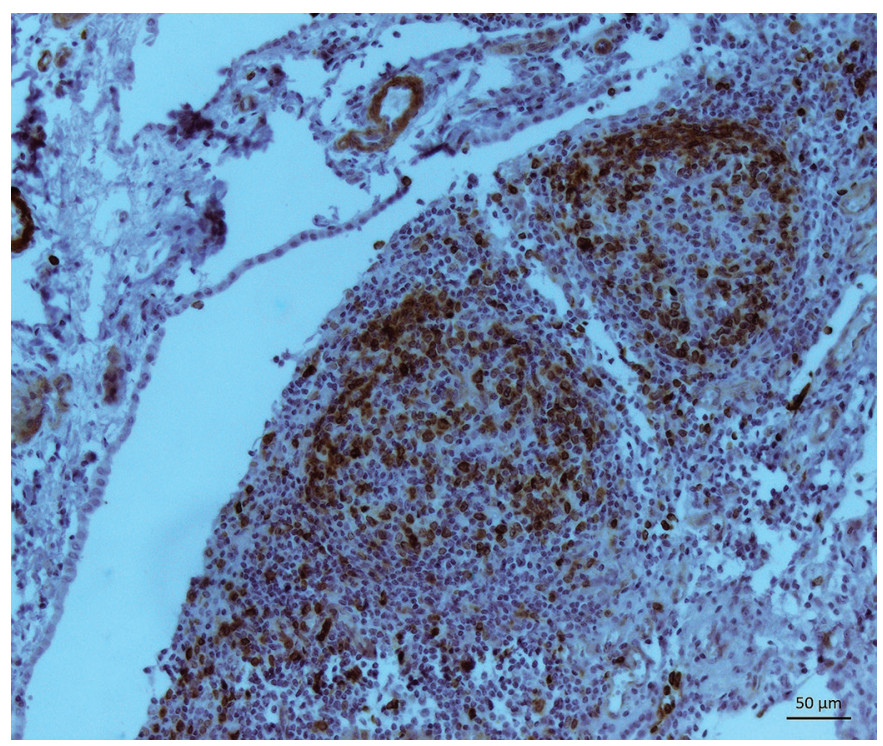

Fig.6. Imuno-histoquímica de diafragma com linfócitos B marcados por anticorpos monoclonais anti-CD79, na polisserosite de búfalo abatido em matadouro. HE, obj.40x.

\section{DISCUSSÃO}

As lesões nas serosas foram observadas em 1,66\% dos bubalinos abatidos no período de estudo (48/2.887). 0 município de Santa Cruz do Arari apresentou a maior porcentagem de casos em relação ao número de animais abatidos $(6,49 \%, 5 / 77)$, seguidos de Santa Bárbara (5,1\%, 5/98) e Santa Luzia do Pará $(5 \%, 1 / 20)$. A maior frequência de casos nos bubalinos oriundos destes municípios em relação aos demais pode estar relacionada a fatores locais ligados ao manejo e/ou constituição dos rebanhos. No entanto, não foi possível acessar estas informações no presente estudo.

As lesões macroscópicas foram muito semelhantes às dos casos descritos por Freitas (1986) e a de alguns dos casos descritos por Oliveira et al. (2016), em especial um caso com marcado envolvimento das serosas. Freitas (1986) caracterizou as lesões como inflamatórias (polisserosite linfocitária) e encontrou associação das mesmas com a infecção por Chlamydia psittaci (Freitas \& Machado 1988, Freitas et al. 1995). Oliveira et al. (2016) caracterizou as lesões como neoplásicas (linfoma multicêntrico de células B) e sugeriu uma possível associação com o vírus da imunodeficiência bovina (BIV), demonstrada em um dos casos. As características histopatológicas dos casos do presente estudo foram compatíveis com inflamação, corroborando a interpretação de Freitas (1986). As lesões nas serosas foram caracterizadas como polisserosite linfocitária, multifocal a coalescente, variando de leve a acentuada.

Adicionalmente, em oito casos do presente estudo, o infiltrado linfocitário formava folículos linfoides ectópicos ou terciários. Os folículos linfoides ectópicos são estruturas transitórias formadas particularmente em reações inflamatórias onde há persistência do patógeno ou antígeno (Neyt et al. 2012, Jones \& Jones 2016). Esta organização do infiltrado na forma de folículos ectópicos foi considerada uma importante evidência da base inflamatória da lesão.

A grande maioria das células linfoides presentes no infiltrado foram CD3 positivas, mas havia também menor 
número de células CD79 positivas. Estas marcações imuno-histoquímicas demonstraram um predomínio de linfócitos T no infiltrado em relação aos linfócitos B. Linfócitos T auxiliares são constituintes importantes dos folículos linfoides terciários (Jones \& Jones, 2016), sendo importantes na sua formação juntamente com as células dendríticas (Neyt et al. 2012, Jones \& Jones 2016). Os linfócitos CD79 positivos predominaram no centro das estruturas foliculares. Este é padrão de distribuição esperado para os linfócitos B em tecidos linfoides secundários e terciários (Neyt et al. 2012, Jones \& Jones 2016). Assim o padrão de distribuição dos linfócitos $\mathrm{T}$ e $\mathrm{B}$ no infiltrado determinado através da imuno-histoquímica também corrobora a base inflamatória da lesão.

Processos inflamatórios em cavidades corpóreas de animais podem ser causados por vírus, bactérias, parasitos, injúrias químicas, mecânicas e/ou por ruptura de órgãos. Os exsudatos fibrinosos, purulentos e granulomatosos são mais frequentes nas serosas de animais (Gelberg 2013). Inflamações linfocitárias como as observadas no presente estudo são incomuns nas serosas de animais, particularmente em búfalos, mas têm sido descritas em associação com Chlamydia psittaci em bubalinos (Freitas 1986, Freitas \& Machado 1988, Freitas et al. 1995). Nos casos do presente estudo, porém, não foram encontrados antígenos de Chlamydia spp. nas lesões através da imuno-histoquímica. Inflamações linfocitárias nas serosas de humanos, com formação de folículos ectópicos, estão ligadas principalmente a respostas a infecções crônicas (como tuberculose, clamidiose por Chlamydia trachomatis), doenças autoimunes (como síndrome de Sjögren, atrite reumatoide e lúpus eritematoso), neoplasias de baixo grau (como mesoteliomas, tumores desmoides e doenças linfoproliferativas) e irritantes ambientais (O'Donnell et al. 2010, Jones \& Jones 2016), mas também podem ocorrer de forma idiopática (O'Donnell et al. 2010). Assim a associação da polisserosite linfocitária de búfalos com outros patógenos ou antígenos não é improvável.

Sete dos 39 casos avaliados no presente estudo apresentaram granulomas tuberculoides no parênquima dos órgãos concomitantes com a inflamação linfocitária nas serosas. A tuberculose em bubalinos assemelha-se a tuberculose bovina e em casos avançados da doença nódulos caseosos com ou sem calcificação podem ser observados nas serosas (Freitas et al. 2001), a chamada tuberculose perlácea ou perolada. No entanto, não foram encontrados granulomas ou bactérias álcool ácido resistentes nas lesões das serosas nos casos do presente estudo. Um envolvimento indireto do infiltrado linfocitário nas serosas com alguns casos de tuberculose em humanos tem sido relatado (O’Donnell et al. 2010) e deve ser considerado nos búfalos quando há concomitância das lesões. A possibilidade do envolvimento de outras doenças infecciosas ou autoimunes, como as relatadas em humanos (O'Donnell et al. 2010, Jones \& Jones 2016), também precisa ser investigada.

Os linfomas de células B envolvendo as serosas também devem ser considerados no diagnóstico diferencial, visto que alguns casos podem estar associados a lesões macroscópicas semelhantes às descritas no presente estudo
(Oliveira et al. 2016). A imuno-histoquímica foi importante para esta diferenciação nos casos do presente trabalho visto que nestes foi demonstrado um predomínio de linfócitos T em relação aos linfócitos B. Exsudação de linfócitos B atípicos em cavidades é descrita em humanos, sendo uma forma rara de linfoma denominada linfoma primário de cavidades ou linfoma efusivo (Brimo et al. 2007). Estes, diferentes dos linfomas dos búfalos descritos acima, não formam massas nas serosas e tecidos linfoides, embora em ambos o envolvimento de imunodeficiência viral seja apontado.

\section{CONCLUSÕES}

Os resultados apresentados permitem concluir que os casos classificados como polisserosite pelos veterinários da inspeção sanitária nos búfalos abatidos para consumo correspondem na histopatologia a um tipo incomum de polisserosite, caracterizada por infiltrado linfocitário, com ocasionais formações de folículos linfoides terciários ou ectópicos.

Foi observado ainda nestas lesões um predomínio de linfócitos T (CD3 positivos) no infiltrado, sendo os linfócitos $\mathrm{B}$ (CD79 positivos) presentes em maior número no interior das estruturas foliculares.

Não foram demonstrados antígenos de clamídias nas lesões do presente estudo, o que demonstra a necessidade de estudos adicionais relativos a(s) etiologia(s) das lesões.

Agradecimentos.- À Universidade Federal do Pará, que pela Pró-Reitoria de Pesquisa e Pós-Graduação (PROPESP) possibilitou a publicação do trabalho pelo Programa de Apoio à Publicação Qualificada (PAPQ). À Adriana de Cássia Lima Dias pelo auxílio fundamental nas técnicas de histopatologia e imuno-histoquímica para clamídias.

\section{REFERÊNCIAS}

Bernardo 0. 2007. Bubalinocultura no Brasil: situação e importância econômica. Revta Bras. Reprod. Anim. 31(3):293-298.

Brimo F., René P.M., Khetani K. \& Auger M. 2007. Primary Effusion Lymphoma A series of 4 cases and review of the literature with emphasis on cytomorphologic and Immunocytochemical differential diagnosis. Cancer Cytopatol. 111(4):224-233.

Casagrande R.A., Machado R.V., Souza O.S., Watanabe T.T.N., Sonne L., Pavarini S.P. \& Driemeier D. 2014. Diagnóstico imuno-histoquímico e caracterização anatomopatológica de clamidiose em psitacídeos. Pesq. Vet. Bras. 34(9):885-890.

Damasceno F.A., Viana J.M., Tinoco I.F.F., Gomes R.C.C. \& Schiassi L. 2010. Adaptação de Bubalinos ao ambiente tropical. Nutritime Revta Eletrôn. 7:1370-1381.

Freitas J.A. 1986. Chlamydia psittaci associada com polisserosite observada em bubalinos abatidos para consumo em Belém, Pará. Dissertação de Mestrado, Faculdade de Veterinária, Universidade Federal Fluminense, Niterói. 67p.

Freitas J.A. \& Machado R.D. 1988. Isolamento de Chlamydia psittaci em búfalos abatidos para consumo em Belém, Pará, Brasil. Pesq. Vet. Bras. 8(2/4):43-50.

Freitas J.A., Machado R.D., Nakamura C., Noronha S.L.B., Ramos O.S. \& Pantaleão F.S.T. 1995. Caracterização de Cepa de Chlamydia psittaci oriunda de Polisserosite de Bubalinos. Arqs Inst. Biológico, São Paulo, 62:(1/2):53-58.

Freitas J.A., Guerra J.L. \& Panetta J.C. 2001. Características da tuberculose observada em búfalos abatidos para consumo: aspectos patológicos e identificação de micobactérias. Braz. J. Vet. Res. Anim. Sci. 38(4):170176. 
Jelocnik M., Forshaw D., Cotter J., Roberts D., Timms P. \& Polkinghorne A. 2014. Molecular and pathological insights into Chlamydia pecorum-associated sporadic bovine encephalomyelitis (SBE) in Western Australia. BMC Vet. Res. 10(121):1-9.

Jones G.W. \& Jones S.T. 2016. Lymphoid folicles: inducible centres for generating antigen-specific imune responses wihin tissues. Immunology 147:141-151.

Maley S.W., Buxton D., Macaldowie C.N., Anderson I.E., Wright S.E., Bartley P.M., Esteban-Redondo I., Hamilton C.M., Storset A.K. \& Innes E.A. 2006. Characterization of the immune response in the placenta of cattle experimentally infected with Neospora caninum in early gestation. J. Comp. Pathol. 135(2/3):130-141.

MAPA 2015. Bovinos e Bubalinos. Ministério da Agricultura Pecuária e Abastecimento. Acessado em 11 jun. 2016.

Gelberg H.B. 2013. Sistema alimentar, peritônio, omento, mesentério e ca- vidade peritoneal, p.324-406. In: McGavin M. \& Zachary F.J. (Eds), Bases da Patologia em Veterinária. 5a ed. Elsevier, Rio de Janeiro.

Neyt K., Perros F., Geurtsvankessel C.H., Hammad H. \& Lambrecht B.N. 2012. Structure and function of lymphoid tissues Tertiary lymphoid organs in infection and autoimmunity. Trends Immunol. 33(6):297-303.

O’ Donnell D.H., Phelan S., McNicholas W., Gallagherb C.G., Crotty T. \& Dodd J.D. 2010. Idiopathic lymphocytic pleuritis: radiographic and high-resolution CT appearances and changes in response to therapy in two adults. Clin. Imaging 34(3):226-230.

Oliveira C.H.S., Barbosa J.D., Damasceno K.A., Cassali G.D., Oliveira C.M.C., Leite R.C. \& Reis J.K.P. 2016 Multicentric lymphoma in buffaloes in the Amazon region, Brazil. BMC Vet. Res. 12(238):1-10.

Ribeiro D.B., Tortelli R. \& Pereira W.L.A. 2015. Estudo anatomo-histopatológico de fígados de bubalinos condenados pelo Serviço de Inspeção Estadual do Pará. Hig. Aliment. 29(248/249):178-183. 